\title{
Mutation-induced metabolite pool alterations in Corynebacterium glutamicum: Towards the identification of nitrogen control signals
}

\author{
Tim Müller ${ }^{\text {a,b }}$, Julia Strösser ${ }^{\text {a }}$, Sebastian Buchinger ${ }^{\text {a }}$, Lars Nolden ${ }^{\text {a, }}$, \\ Astrid Wirtz ${ }^{\mathrm{a}}$, Reinhard Krämer ${ }^{\mathrm{a}}$, Andreas Burkovski ${ }^{\mathrm{a}, \mathrm{c}, *}$ \\ a Institut für Biochemie, Universität zu Köln, Germany \\ b International Max Planck Research School, Max-Planck-Institut für Züchtungsforschung, Köln, Germany \\ c Lehrstuhl für Mikrobiologie, Friedrich-Alexander-Universität Erlangen-Nürnberg, Erlangen, Germany
}

Received 13 February 2006; received in revised form 17 May 2006; accepted 26 May 2006

\begin{abstract}
The influence of glutamate dehydrogenase activity on nitrogen regulation in Corynebacterium glutamicum was investigated. As shown by RNA hybridization experiments deletion of the $g d h$ gene results in a rearrangement of nitrogen metabolism. Even when sufficiently supplied with nitrogen sources, a $g d h$ deletion strain showed the typical nitrogen starvation response of $C$. glutamicum. These changes in transcription correlate with distinct alterations of intracellular metabolite pattern. Metabolite analyses of different mutant strains and the wild type indicated that ammonium and 2-oxoglutarate might influence the nitrogen regulation system of $C$. glutamicum cells.
\end{abstract}

(c) 2006 Elsevier B.V. All rights reserved.

Keywords: Corynebacterium; Glutamate dehydrogenase; Nitrogen control; Nitrogen regulation

\footnotetext{
* Corresponding author at: Lehrstuhl für Mikrobiologie, FriedrichAlexander-Universität Erlangen-Nürnberg, Staudtstr. 5, 91058 Erlangen, Germany. Tel.: +499131 85 28086; fax: +4991318528082 .

E-mail address: aburkov@biologie.uni-erlangen.de (A. Burkovski).

1 Present address: Universität Bonn, Institut für Rekonstruktive Neurobiologie, Bonn, Germany.
}

\section{Introduction}

Corynebacterium glutamicum is a gram-positive soil bacterium belonging to the group of mycolic acidcontaining actinomycetes (Chun et al., 1996). It was isolated by Kinoshita et al. (1957) in a screening program for L-glutamate-producing bacteria from a soil sample collected at Ueno Zoo in Tokyo and at that time designated as Micrococcus glutamicus (Udaka, 1960). Today, large amounts of L-glutamate (more than 
$1,500,000$ tonnes per year) and L-lysine (more than 560,000 tonnes per year) are produced by use of different $C$. glutamicum strains, in addition to smaller amounts of L-alanine, L-isoleucine and L-proline and in addition to different nucleotides (Leuchtenberger, 1996; Hermann, 2003).

Due to its pivotal role in glutamate production, basic biochemical work on the glutamate-producing enzymes of $C$. glutamicum was already started in the 1960s (Kimura, 1962; Oshima et al., 1964; Shiio and Ozaki, 1970; Tochikura et al., 1984). As most bacteria, C. glutamicum has two primary pathways to facilitate the incorporation of ammonium into the key nitrogen donors for biosynthetic reactions, L-glutamate and Lglutamine (Shiio and Ozaki, 1970; Jakoby et al., 1997; Tesch et al., 1998). Glutamate dehydrogenase (GDH) assimilates ammonium by the reductive amination of 2oxoglutarate to L-glutamate. Alternatively, ammonium is assimilated via the glutamine synthetase/glutamate synthase (GS/GOGAT) pathway, whereby ammonium is used to amidate $\mathrm{L}$-glutamate under consumption of ATP to form L-glutamine by glutamine synthetase (GS). The amide group is then transferred reductively to 2-oxoglutarate by glutamate synthase (GOGAT), resulting in the net conversion of 2-oxoglutarate to Lglutamate. Assimilation via glutamate dehydrogenase is bioenergetically more favourable, as the GS/GOGAT pathway utilizes an additional mol ATP per mol ammonium assimilated. Consequently, GDH is preferentially used in ammonium-rich medium, while transcription of $g l t B D$, coding for GOGAT, is completely repressed in this situation (Beckers et al., 2001; Schulz et al., 2002) and transcription of $g \ln A$, coding for GS, is maintained at a basal level to provide L-glutamine for growth (Nolden et al., 2001a). When the cells face nitrogen limitation, assimilation via GDH is not sufficient due to the low affinity of the enzyme. In this situation, expression of $g \ln A$ and $g l t B D$ is activated and the GS/GOGAT pathway is preferentially used for ammonium assimilation.

In C. glutamicum the TetR-family transcriptional regulator AmtR was identified as the master regulator of nitrogen control (Jakoby et al., 2000; Beckers et al., 2005). Under conditions of high nitrogen supply AmtR blocks the transcription of nitrogen-controlled genes, e.g. $g \ln A$ and $g l t B D$. In response to nitrogen limitation, repression is relieved by an interaction of AmtR with the GlnK signal transduction protein (Beckers et al.,
2005). Adenylylation of GlnK by the GlnD protein is crucial for derepression of transcription, since unmodified GlnK does not interact with AmtR (Beckers et al., 2005). In response to an improved nitrogen supply, GlnD deadenylylates GlnK again, resulting in repression of AmtR-controlled genes (Strösser et al., 2004). It is unknown how this regulation process is triggered in C. glutamicum, i.e. which metabolite(s) indicate(s) the nitrogen status of the cell and how this signal is transferred to the GlnD/GlnK/AmtR signal cascade.

In this study, we investigated the influence of glutamate dehydrogenase activity on nitrogen regulation in $C$. glutamicum. The $g d h$ gene, encoding glutamate dehydrogenase, was isolated by Börmann et al. (1992) and mutant strains were characterized. Despite the high enzymatic activity of $1.3 \mathrm{U}$ (mg protein) ${ }^{-1}$ determined for C. glutamicum wild type GDH (Tesch et al., 1998), deletion of the $g d h$ gene revealed astonishingly no detrimental effect on growth. Moreover, glutamate production was unaffected as well (Börmann et al., 1992; Börmann-El Kholy et al., 1993). Later, Tesch et al. (1998) observed a significantly enhanced activity of GS and GOGAT in the $g d h$ deletion strain under nitrogen surplus, which might complement the lack of GDH activity. In this communication, we show that the activation of the GS/GOGAT pathway on expression level in a $g d h$ deletion strain is triggered by characteristic changes in the metabolite pool of $C$. glutamicum leading to a nitrogen starvation response of the global nitrogen regulation network.

\section{Materials and methods}

\subsection{Bacterial strains and growth conditions}

Strains and plasmids used in this study are listed in Table 1. Bacteria were routinely grown in Luria Bertani (LB) medium (Sambrook et al., 1989) at $30^{\circ} \mathrm{C}($ C. glutamicum $)$ or $37^{\circ} \mathrm{C}$ (Escherichia coli). LB medium for $C$. glutamicum strains was supplemented with $2 \%$ glucose (final concentration) and antibiotics were added in standard concentrations if appropriate (Ausubel et al., 1987). For cell culture, a standard inoculation scheme was applied. A fresh C. glutamicum culture in LB medium was used to inoculate minimal medium (Keilhauer et al., 1993) with an excess of nitrogen sources (approximately $500 \mathrm{mM}$ ammonium) 
Table 1

Strains and plasmids used in this study

\begin{tabular}{|c|c|c|}
\hline Strains/plasmids & Relevant genotype/description & Reference \\
\hline \multicolumn{3}{|l|}{ C. glutamicum } \\
\hline ATCC 13032 & Wild type & Abe et al. (1967) \\
\hline $\mathrm{LN} \Delta \mathrm{GDH}$ & ATCC $13032 \Delta g d h$ & This study \\
\hline $\mathrm{LN} \Delta \mathrm{GS}$ & ATCC $13032 \Delta g \ln A$ & This study \\
\hline \multicolumn{3}{|l|}{ E. coli } \\
\hline DH5 $\alpha \mathrm{mcr}$ & supE44 hsdR17 recA1 endA1 gyrA96 thil relA mcrA $\Delta(\mathrm{mrr}$-hsdRMS-mcrBC $)$ & Grant et al. (1990) \\
\hline \multicolumn{3}{|l|}{ Plasmids } \\
\hline pGEM3z & E. coli plasmid for in vitro transcription, $\mathrm{Ap}^{\mathrm{R}}$ & Promega, Mannheim \\
\hline pGEM $4 \mathrm{z}$ & E. coli plasmid for in vitro transcription, $\mathrm{Ap}^{\mathrm{R}}$ & Promega, Mannheim \\
\hline pGEMamtA & $0.5 \mathrm{~kb}$ internal $a m t A$ fragment in pGEM $3 \mathrm{z}$ & Jakoby et al. (2000) \\
\hline pGEMamtB & $1.0 \mathrm{~kb}$ internal $\mathrm{am} t B$ fragment in pGEM $3 \mathrm{z}$ & Jakoby et al. (2000) \\
\hline pGEMgdh & $0.6 \mathrm{~kb}$ internal $g d h$ fragment in $\mathrm{pGEM} 4 \mathrm{z}$ & This study \\
\hline pGEMglnD & $0.7 \mathrm{~kb}$ internal $g \ln D$ fragment in pGEM $3 \mathrm{z}$ & Jakoby et al. (2000) \\
\hline pGEMglnK & $0.3 \mathrm{~kb}$ internal $g \ln K$ fragment in pGEM $3 \mathrm{z}$ & Jakoby et al. (2000) \\
\hline pGEMglnA & $0.5 \mathrm{~kb}$ internal $g \ln A$ fragment in $\mathrm{pGEM} 3 \mathrm{z}$ & Nolden et al. (2001b) \\
\hline pGEMgltB & $0.5 \mathrm{~kb}$ internal $\mathrm{glt} B$ fragment in pGEM $3 \mathrm{z}$ & Beckers et al. (2001) \\
\hline pK18mobsacB & Vector for generation of unmarked gene deletions, $\operatorname{sacB}, \mathrm{Ap}^{\mathrm{R}}$ & Schäfer et al. (1994) \\
\hline pK18gdh & Plasmid pK18mobsacB carrying the flanking DNA regions of the $g d h$ gene & This study \\
\hline $\mathrm{pK} 18 \mathrm{~g} \ln \mathrm{A}$ & Plasmid pK18mobsacB carrying the flanking DNA regions of the $g \ln A$ gene & This study \\
\hline
\end{tabular}

Abbreviations: $\mathrm{Ap}^{\mathrm{R}}$, resistance to ampicillin; $\mathrm{Km}^{\mathrm{R}}$, resistance to kanamycin.

for overnight growth. This culture, with an overnight $\mathrm{OD}_{600}$ of approximately 25-30, was used to inoculate fresh minimal medium to an $\mathrm{OD}_{600}$ of approximately 1.0 and cells were grown until the exponential growth phase was reached $\left(\mathrm{OD}_{600}\right.$ approximately 4-5). To induce nitrogen starvation, cells were harvested by centrifugation and the pellet was suspended in prewarmed minimal medium without nitrogen source. The nitrogen-deprived cells were incubated at $30^{\circ} \mathrm{C}$ under aeration. Subsequently, $200 \mathrm{mM}$ of ammonium (final concentration) were added to a culture of nitrogenstarved cells in order to improve the nitrogen supply again.

\subsection{General molecular biology techniques}

For plasmid isolation, transformation and cloning steps, standard techniques were used (Ausubel et al., 1987; Sambrook et al., 1989). E. coli strain DH5 $\alpha \mathrm{mcr}$ was used as a cloning host. Competent C. glutamicum cells were prepared according to van der Rest et al. (1999). Chromosomal C. glutamicum DNA was isolated as described (Eikmanns et al., 1994). DNA sequence analyses were carried out by the bioanalytics service unit at the Center for Molecular Medicine Cologne.

\subsection{Construction of RNA probes, RNA preparation and northern hybridization analysis}

An internal $0.6 \mathrm{~kb} g d h$ fragment was amplified via PCR using chromosomal DNA from ATCC 13032 as template. For subsequent cloning steps, $\mathrm{XbaI}$ and EcoRI restriction sites (shown in bold) were introduced in the primer sequences $\left(5^{\prime}\right.$-GCGCGC TCTAGAGTGCGAGCCTGAGCGTCA-3'/5'-GCGCGCGAATTCGGAGCTTAGCCACGTCAA-3').

After restriction of the PCR product with EcoRI and $X b a \mathrm{I}$, the $g d h$ fragment was ligated to vector pGEM4z (Promega, Heidelberg), leading to plasmid pGEMgdh. After linearization by $\mathrm{Xba \textrm {I }}$ this DNA was used for in vitro transcription to generate a dioxigenin-labelled RNA probe using SP6 RNA polymerase and the DIG RNA Labelling Mix (Roche Diagnostics, Mannheim).

Total RNA was prepared after disruption of the C. glutamicum cells by glass beads using the Nucleo Spin RNA II Kit as recommended by the supplier (Macherey-Nagel, Düren). The RNA was spotted directly onto nylon membranes using a Schleicher and Schuell (Dassel) Minifold I Dot Blotter. Hybridization of digoxigenin-labelled RNA probes was detected with a Fuji luminescent image analyser LAS1000 or Kodak X-OMAT X-ray films using 
alkaline phosphatise-conjugated anti-digoxigenin fab fragments and CSPD as light-emitting substrate as recommended by the supplier (Roche Diagnostics, Mannheim).

\subsection{Construction of $g d h$ and glnA deletion strains}

Unmarked chromosomal deletions were introduced into the C. glutamicum genome using the protocol described by Schäfer et al. (1994). In order to generate a $g d h$ deletion, a DNA fragment spanning the $g d h$ gene together with its flanking sequences $(1.5 \mathrm{~kb}$ upand downstream of $g d h$ ) was amplified via PCR using chromosomal DNA from ATCC 13032 as template. For subsequent cloning steps, HindIII and EcoRI restriction sites (shown in bold) were introduced in the primer sequences (5'-GCGCGCGAATTCATCAAGATCGTCAGCAGTGG-3' $3^{\prime} / 5^{\prime}$-GCGCGCAAGCTTATGTGGATCGGATAATTGACCTG-3'). After restriction with EcoRI and HindIII, the PCR product was ligated to vector pK18mobsacB. A $500 \mathrm{bp}$ EcoRV/BamHI fragment of the $g d h$ gene was removed from the plasmid. After treatment with Mung Bean Nuclease (NEB, Schwalbach), the plasmid was religated. The resulting plasmid, $\mathrm{pK} 18 \Delta g d h$, was used for the chromosomal deletion via two independent recombination events as described (Schäfer et al., 1994).

For construction of a chromosomal $g \ln A$ deletion, a DNA fragment spanning the $g \ln A$ gene together with its flanking sequences $(2.8 \mathrm{~kb})$ was amplified via PCR using chromosomal DNA from ATCC 13032 as template. For subsequent cloning steps, $\mathrm{XbaI}$ and HindIII restriction sites (shown in bold) were introduced in the primer sequences (5'-GCGCGCTCTAGAATCAAGATCGTCAGCAGTGG-3'/5'-GCGCGCAAGCTTTGGTTAACCTCAAAGGCATCGACG-3'). After restriction with $X b a \mathrm{I}$ and HindIII, the PCR product was ligated to vector pUC19. A $1.2 \mathrm{~kb} B s m \mathrm{I} / B g l \mathrm{II}$ fragment of the $g \ln A$ gene was removed from the plasmid. After treatment with Mung Bean Nuclease (NEB, Schwalbach), the plasmid was re-ligated. The resulting plasmid was restricted with XbaI and HindIII and the $1.6 \mathrm{~kb}$ insert was ligated to vector pK18mobsacB. The resulting plasmid, pK18 $\Delta$ glnA, was used for the chromosomal deletion via two independent recombination events as described (Schäfer et al., 1994).

\subsection{Western blotting}

For the preparation of $C$. glutamicum cell extracts, aliquots were transferred from the culture to tubes containing glass beads and immediately frozen in liquid nitrogen. Samples thawed on ice were disrupted using a FastPrep FP120 instrument (Q-BIOgene, Heidelberg) placed in a cooling chamber. Subsequently, glass beads and cell debris were removed by centrifugation. Protein concentrations were determined using Roti-Nanoquant as recommended by the supplier (Carl Roth, Karlsruhe) using bovine serum albumin as a standard. SDS-PAGE was carried out using $12 \%$ acrylamide gels and a tricine buffer system as described by Schägger and von Jagow (1987). After electrophoresis, the gel-separated proteins were transferred onto a polyvinylidene difluoride membrane (PVDF; Carl Roth, Karlsruhe) by electroblotting and incubated with GlnK-specific antiserum. Antibody binding was visualized by appropriate secondary antibodies coupled to alkaline phosphatase or peroxidase (Sigma-Aldrich, Darmstadt) and the BCIP/NBT alkaline phosphatase substrate (Sigma-Aldrich, Darmstadt).

\subsection{Determination of internal 2-oxoglutarate and L-glutamate}

Ten milliliters of a $C$. glutamicum culture $\left(\mathrm{OD}_{600}\right.$ approximately 4-5) were harvested by centrifugation $(10 \mathrm{~min}, 4000 \times \mathrm{g})$. The supernatant was removed and the cell pellet was washed with pre-warmed fresh culture medium and then re-suspended in $1 \mathrm{ml}$ methanol. After incubation for $20 \mathrm{~min}$ at $70^{\circ} \mathrm{C}$, cell debris was removed by centrifugation. The supernatant was dried at $60^{\circ} \mathrm{C}$ under continuous nitrogen flow. The residue was dissolved in $50 \mu \mathrm{l}$ of a solution of $20 \mathrm{~g} / \mathrm{l}$ methoxylamine in pyridine and incubated for $90 \mathrm{~min}$ at $30^{\circ} \mathrm{C}$. Eighty microliters of $\mathrm{N}$-methyltrimethylsilyltrifluoroacetamide (MSTFA) were added followed by an incubation of $60 \mathrm{~min}$ at $65^{\circ} \mathrm{C}$. The concentration of derivatized 2-oxoglutarate and L-glutamate were measured by gas chromatography using the TraceGC system (Thermo Finnigan, Woburn) and a FS-Supreme 5 column (CSChromatographie, Langenwehe). After an injection of $0.3 \mu \mathrm{l}$ (split ratio 1:25), separation was achieved under nitrogen gas flow (flow rate: $1 \mathrm{ml} / \mathrm{min}$ ) using the following time program: $2 \mathrm{~min}$ at $60^{\circ} \mathrm{C}$, temperature gra- 
dient of $30^{\circ} \mathrm{C} / \mathrm{min}$ to $140{ }^{\circ} \mathrm{C}$, temperature gradient of $2{ }^{\circ} \mathrm{C} / \mathrm{min}$ to $175^{\circ} \mathrm{C}$, temperature gradient of $30^{\circ} \mathrm{C} / \mathrm{min}$ to $320^{\circ} \mathrm{C}, 5 \mathrm{~min}$ at $320^{\circ} \mathrm{C}$. At the end of the run, initial conditions were restored. Column effluents were monitored by flame ionization detection (FID) at $300^{\circ} \mathrm{C}$. Internal concentration were calculated from the data using a dry weight of $0.35 \mathrm{mg} / \mathrm{ml} \mathrm{OD}_{600}=1$ and an internal volume of $2.0 \mu \mathrm{l} / \mathrm{mg}$ dry weight.

\subsection{Determination of ammonium}

Two microliters of a $C$. glutamicum culture $\left(\mathrm{OD}_{600}\right.$ approximately 4-5) were harvested by centrifugation $(5 \mathrm{~min}, 13,000 \times \mathrm{g})$. The weight of the pellet was determined and the cells were resuspended in $100 \mu \mathrm{l}$ of an aqueous $0.1 \% \mathrm{~N}$-cetyl- $\mathrm{N}, \mathrm{N}, \mathrm{N}$-trimethylammonium bromide (CTAB) solution. After incubation for $10 \mathrm{~min}$ at room temperature, cell debris was removed by centrifugation. The ammonium concentrations of this supernatant (cell extract) as well as of the supernatant obtained in the first centrifugation step (culture medium) were determined by reversed-phase HPLC using a protocol based on the method described by Lindroth and Mopper (1979). Ammonium was labelled by pre-column derivatisation using orthophthaldialdehyde (OPA). For separation, the Agilent 1100 system (Agilent, Waldbronn) with a LiChrospher RP $18(150 \mathrm{~mm} \times 3 \mathrm{~mm}, 5 \mathrm{~mm})$ column (Merck, Darmstadt) and $60 \%$ methanol as mobile phase with a low rate of $0.8 \mathrm{ml} / \mathrm{min}$ at $40^{\circ} \mathrm{C}$ were used. Column effluents were monitored with a G1321A Fluorimenter (Agilent, Waldbronn) at an excitation wavelength of $330 \mathrm{~nm}$ and a detection wavelength of $455 \mathrm{~nm}$.

\subsection{Calculation of intracellular ammonium concentrations}

From the ammonium concentrations of cell extract and culture medium measured by HPLC, the intracellular ammonium concentration can be calculated. As a prerequisite for this calculation, the ratio of internal cell volume to total pellet volume had to be determined. For this purpose, the distribution of a membrane permeable probe, $\left[{ }^{3} \mathrm{H}\right]$-labelled water, a membrane impermeable one, and $\left[{ }^{14} \mathrm{C}\right]$-labelled taurine, was measured. About $62.0 \pm 1.0 \%$ of the cell pellet consisted of surrounding medium. Internal concentration were calculated from the data using a dry weight of $0.35 \mathrm{mg} / \mathrm{ml} \mathrm{OD}_{600}=1$ and an internal volume of $2.0 \mu \mathrm{l} / \mathrm{mg}$ dry weight (for determination of cytoplasmic volumes depending on media composition, see Rönsch et al., 2003).

\subsection{Determination of internal $\mathrm{L}$-glutamine}

One milliliter of a C. glutamicum cell culture $\left(\mathrm{OD}_{600}\right.$ approximately 4-5) was separated from the surrounding medium by rapid filtration (within less than $30 \mathrm{~s}$ ). The cells were washed with pre-warmed fresh culture medium and then re-suspended in $1 \mathrm{ml}$ of an aqueous solution of $0.1 \%$ CTAB. After incubation for $10 \mathrm{~min}$ at room temperature, cell debris was removed by centrifugation. The L-glutamine concentration of the supernatant was determined by reversed-phase HPLC. L-Glutamine was labelled by pre-column derivatisation using ortho-phthaldialdehyde (OPA). For separation, the Agilent 1100 system (Agilent, Waldbronn) with a 125/4 Nucleodur 100-5 C18 ec column (Macherey-Nagel, Düren) was used. The following buffer system was applied: (A) $40 \mathrm{mM}$ sodium acetate buffer (pH 6.5):methanol:acetonitrile (95:2.5:2.5); (B) methanol:acteonitrile (50:50). Column effluents were monitored with a G1321A fluorimeter (Agilent, Waldbronn) at an excitation wavelength of $330 \mathrm{~nm}$ and a detection wavelength of $455 \mathrm{~nm}$. Internal concentration were calculated from the data using a dry weight of $0.35 \mathrm{mg} / \mathrm{ml} \mathrm{OD}_{600}=1$ and an internal volume of $2.0 \mu \mathrm{l} / \mathrm{mg}$ dry weight.

\subsection{Metabolome analysis by gas chromatography/mass spectrometry}

Sample preparation and mass spectrometry was carried out using the protocol described by Strelkov et al. (2004) with slight modifications. In short, approximately $5 \times 10^{10}$ cells were harvested at the exponential growth phase. Samples were centrifuged $(4500 \times g$, $3 \mathrm{~min}, 4^{\circ} \mathrm{C}$ ) and cells were washed with $20 \mathrm{ml} 0.9 \%$ $\mathrm{NaCl}$ at $4{ }^{\circ} \mathrm{C}$. Intracellular metabolites were extracted by ultrasonification of the harvested cells for $15 \mathrm{~min}$ at $70{ }^{\circ} \mathrm{C}$ in $1.5 \mathrm{ml}$ methanol (containing $8 \mathrm{mg} / \mathrm{ml}$ ribitol as internal standard). Samples were chilled on ice for $2 \mathrm{~min}, 1.5 \mathrm{ml}$ water was added and the samples were mixed thoroughly. Subsequently, $1 \mathrm{ml}$ of chloroform was added and samples were mixed again in order to remove lipophilic compounds from the polar phase. Finally, phases were separated by centrifugation 
$5 \mathrm{~min}$ at $3900 \times g$ and $1 \mathrm{ml}$ of the polar methanol/water phase was transferred into a new $2 \mathrm{ml}$ sample tube and dried under vacuum (Speedvac Concentrator, Eppendorf, Hamburg, Germany).

For derivatization dried samples were resolved in $20 \mu \mathrm{l}$ pyridine (Fluka-Sigma-Aldrich Co., Taufkirchen, Germany) containing $20 \mathrm{mg} / \mathrm{ml}$ methoxyamine (Fluka-Sigma-Aldrich Co., Taufkirchen, Germany) and incubated for $90 \mathrm{~min}$ at $30^{\circ} \mathrm{C}$ under agitation. Subsequently, $32 \mu \mathrm{l} \quad N$-methyl- $N$-trimethylsilyltrifluoroacetamide (MSTFA, CS Chromatography Service GmbH, Langerwehe, Germany) were added, followed by an incubation for $30 \mathrm{~min}$ at $37^{\circ} \mathrm{C}$ and $2 \mathrm{~h}$ at $25^{\circ} \mathrm{C}$. Four microliters of a mixture of eight different alkanes $\left(\mathrm{C}_{10}, \mathrm{C}_{12}, \mathrm{C}_{15}, \mathrm{C}_{19}, \mathrm{C}_{22}, \mathrm{C}_{28}, \mathrm{C}_{32}, \mathrm{C}_{36}, 0.2 \%\right.$ in cyclohexane each) was added for the calibration of retention indices according to van den Dool and Kratz (1963). Two microliters of the derivatized samples were injected in a Finnigan Trace Gas Chromatograph (ThermoFinnigan, San Jose, USA) equipped with a DB-5MS column (J\&W Scientific, Folsom, USA). Eluted compounds were analysed with a Trace Mass Spectrometer (ThermoFinnigan, San Jose, USA) after electron impact ionization. All parameters for sample injection, gas chromatography and mass spectrometry were described elsewhere (Strelkov et al., 2004).

\section{Results}

\subsection{Deletion of the gdh gene affects nitrogen control}

Tesch et al. (1998) showed previously high GOGAT activity in a glutamate dehydrogenase-deficient strain without studying the molecular background of this observation. We assumed that glutamate synthase activation occurs on the level of transcription and, therefore, tested transcription of the gltB gene. For this purpose, RNA was isolated from the wild type ATCC 13032 and $g d h$ deletion strain $\mathrm{LN} \Delta \mathrm{GDH}$, grown under conditions of high nitrogen supply (approximately $500 \mathrm{mM}$ ammonium), during nitrogen starvation and after addition of ammonium to nitrogenstarved cells. The RNA hybridization experiments carried out revealed that deletion of $g d h$ leads to the deregulation of transcription of gltB (Fig. 1A). This result explains the observed phenotype of a $g d h$ mutant strain and the high glutamate synthase activity observed by Tesch et al. (1998).

In order to elucidate whether $g l t B$ deregulation is caused by a specific effect or by a so far unknown derepression of the AmtR regulon in spite of nitrogen surplus conditions, additionally, expression of other AmtR-controlled genes was investigated. In fact, transcription of $g \ln A$, encoding glutamine synthetase, $g \ln D$, coding for the GlnK-modifying/demodifying enzyme, $g \ln K$, encoding the central nitrogen signal transduction protein $\mathrm{GlnK}$, and the ammonium transporter encoding $a m t A$ and $a m t B$ genes were tested and found to be derepressed in the $g d h$ deletion strain (for $g l t B, g \ln A$ and $g \ln D$ expression see Fig. 1A, data for other genes not shown).

For the release of the AmtR repressor from its target DNA, an interaction with adenylylated GlnK protein is crucial (Beckers et al., 2005). Typically, GlnK is synthesized and adenylylated during nitrogen starvation only (Nolden et al., 2001b; Strösser et al., 2004). To test whether the $g d h$ deletion influences GlnK synthesis and modification, Western blot analyses were carried out. These experiments showed that GlnK was in contrast to the wild type present in high amounts and at least is partially adenylylated in the $g d h$ mutant $\mathrm{LN} \Delta \mathrm{GDH}$ even under nitrogen surplus conditions (Fig. 1B), explaining the transcription of AmtR-regulated genes.

The reason for the induction of nitrogen starvation response in a $g d h$ deletion strain was unclear. Since we assumed that the deregulatory effect of a $g d h$ deletion might be caused by changes in the concentration of a metabolite, which serves as an indicator for the nitrogen status of the cell, we investigated the concentrations of different metabolites in wild type and mutant strain.

\subsection{Influence of glutamate dehydrogenase on intracellular metabolite pools}

Glutamate dehydrogenase activity influences the concentrations of its product glutamate and its educts 2-oxoglutarate and ammonium. Indirectly, also the Lglutamine concentration might be influenced. Consequently, we focused on the determination of these metabolites in order to elucidate which metabolite might be responsible for deregulation of nitrogen control in C. glutamicum. For this purpose C. glutamicum wild type strain ATCC 13032 and $g d h$ deletion strain $\mathrm{LN} \Delta \mathrm{GDH}$ were cultivated in nitrogen-rich min- 


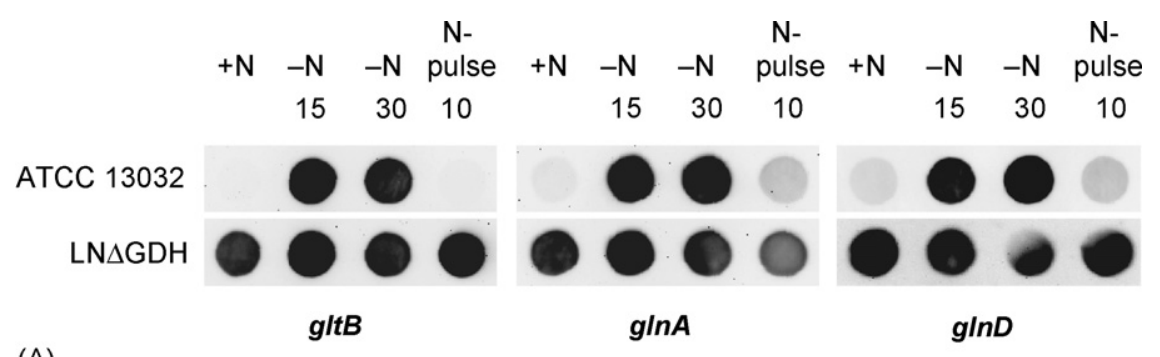

(A)

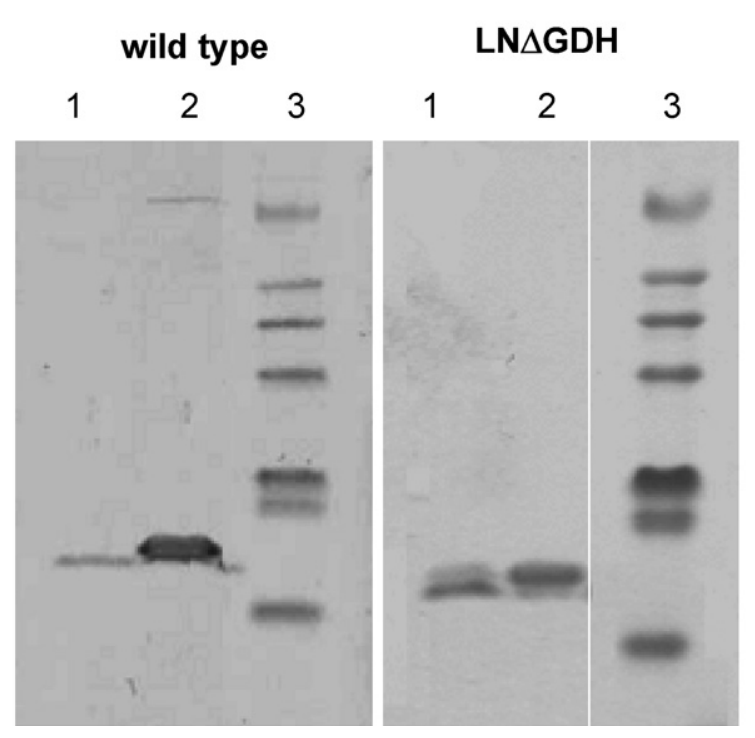

Fig. 1. (A) RNA dot blot hybridization experiment. Total RNA was isolated from wild type ATCC 13032 and $g d h$ deletion strain LN $\Delta$ GDH cultivated under nitrogen excess $(+\mathrm{N})$, after 15 , respectively, $30 \mathrm{~min}$ of nitrogen starvation $(-\mathrm{N} 15,-\mathrm{N} 30)$ and $10 \mathrm{~min}$ after an excess of ammonium was added (N pulse 10). The RNA was hybridized with antisense probes directed against $g \operatorname{lt} B, g \ln A$ and $g \ln D$ transcripts. (B) GlnK synthesis and modification in strain ATCC 13032 and LN $\triangle$ GDH. Cytoplasmic proteins were prepared from cells grown in nitrogen-rich medium (1) and nitrogen-deprived cells (2), separated by SDS-PAGE (25 $\mu \mathrm{g} / \mathrm{lane})$, blotted and probed with antibodies directed against nitrogen signal transduction protein GlnK. The upper band corresponds to the adenylylated protein, the lower band to unmodified GlnK (Strösser et al., 2004). (3) Molecular weight marker (MBI fermentas prestained proteinmarker broad range, from top to bottom: 70, 55, 45, 35, 25, 15 and 10 kDa).

imal medium and the internal concentrations of 2oxoglutarate, ammonium, glutamate and glutamine were measured by HPLC and gas chromatography, respectively.

In the two strains, almost identical L-glutamine concentrations (about $15 \mathrm{mM}$ ) were observed (Fig. 2A). L-Glutamate and ammonium concentrations were differing between ATCC 13032 and LN $\Delta$ GDH (Fig. 2B and $\mathrm{C}$ ). However, these concentrations were very high in any case, making them a unlikely signal for a starvation condition. Only the 2-oxoglutarate concentration in strain LN $\Delta \mathrm{GDH}$ exceeded the wild type concentration by a factor of 3.5 (Fig. 2D) making 2-oxoglutarate a likely candidate for the deregulation of nitrogen control in the $g d h$ deletion strain.

To test, if 2-oxoglutarate is also a marker of nitrogen supply in the wild type, ATCC 13032 cells were starved for nitrogen sources and internal solute concentrations were determined. In the wild type, starvation for $30 \mathrm{~min}$ resulted only in a slight decrease of the glutamate pool from $143 \pm 18$ to $98 \pm 16 \mathrm{mM}$ (Fig. 3B). This observation is in accord with previous data, which showed that the glutamate pool reacts only very slowly to nitrogen starvation (Nolden et al., 2001b). Since the transcriptional response to starvation occurs within minutes, glutamate can be excluded as an indicator 

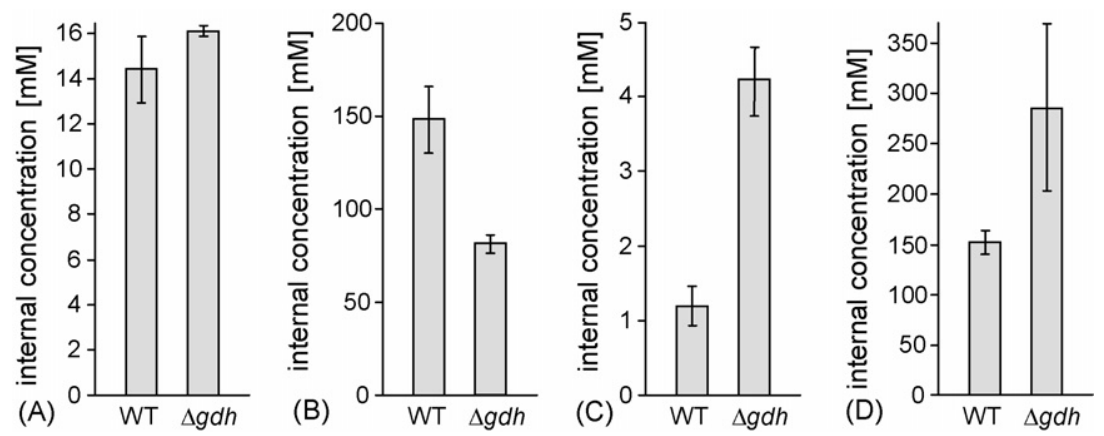

Fig. 2. Intracellular metabolite concentrations in ATCC 13032 and LN $\Delta$ GDH cells. The intracellular concentrations of L-glutamine (A), Lglutamate (B), 2-oxoglutarate (C) and ammonium (D) were determined by gas chromatography and HPLC analysis from wild type and LN $\Delta$ GDH cells grown in nitrogen-rich minimal medium.

of the nitrogen status of the cell. Interestingly, also the internal concentration of 2-oxoglutarate was constantly at $1.2 \mathrm{mM}$ under nitrogen surplus as well as under nitrogen starvation in the wild type (Fig. 3C). In contrast, the internal concentrations of L-glutamine and ammonium were high during nitrogen surplus but significantly diminished in response to nitrogen starvation. Glutamine concentrations decreased from 14.4 to $1.7 \mathrm{mM}$, while ammonium concentrations decreased from 152 to $2 \mathrm{mM}$ (Fig. 3A and D). Thus, the internal concentrations of ammonium and glutamine correlated with the nitrogen supply, i.e. the availability of ammonium in the surrounding medium, while no changes of 2-oxoglutarate were observed in the C. glutamicum wild type under the tested conditions. This discrepancy between $g d h$ deletion and wild type strain might be explained by their different ammonium assimilation capacity. While in the $g d h$ deletion strain nitrogen metabolism is at least partially blocked, this is not the case in the wild type. Therefore, sampling times used for experiment might be too slow to detect regulatory important transient changes of metabolites in the wild type.

\subsection{Analysis of metabolites and $G \ln K$ adenylylation state}

For more time-resolved analysis of the wild type nitrogen starvation response, cells were grown in nitrogen-rich minimal medium, transferred to nitrogenfree medium and then treated with an ammonium pulse. At different time points samples were analyzed in respect to metabolite alterations, gltB expression and GlnK adenylylation state.

To determine metabolite concentrations, gas chromatography/mass spectrometry was used. This method
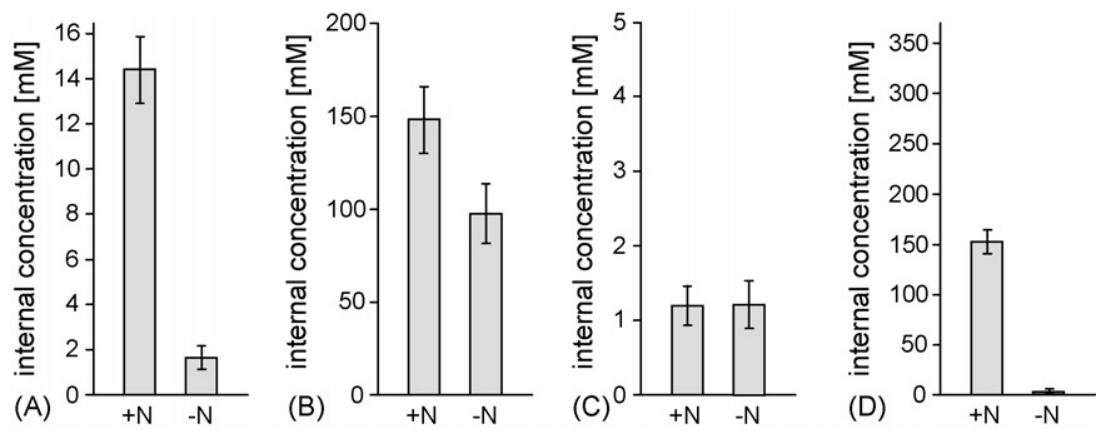

Fig. 3. Intracellular metabolite concentrations in strain ATCC 13032 depending on the nitrogen supply. The intracellular concentrations of L-glutamine (A), L-glutamate (B), 2-oxoglutarate (C) and ammonium (D) were determined by gas chromatography and HPLC analysis from wild type cells grown under nitrogen surplus $(+\mathrm{N})$ and incubated in nitrogen-free minimal medium for $30 \mathrm{~min}(-\mathrm{N})$. 
is well suited to detect relative changes caused by mutations or changed environmental conditions (Strelkov et al., 2004). When cells were harvested and re-suspended in nitrogen-free minimal medium, a slight increase of 2-oxoglutarate was observed, most likely due to the centrifugation step. During the next 30 min of nitrogen starvation, the 2-oxoglutarate pool increased steadily up to a factor of about 30 . In response to the addition of ammonium, the initial level of 2-oxoglutarate was reached almost immediately. Adenylylation of GlnK and transcription of $g l t B$ were correlated to a low 2oxoglutarate pool. As a consequence, it is very likely that 2-oxoglutarate indicates the nitrogen supply of the wild type as well. A similar correlation of L-glutamate and L-glutamine was not found. However, due to the experimental design, GlnK adenylylation was also correlated with ammonium availability. It is noteworthy in this respect that nitrogen starvation response is not fully activated in strain $\mathrm{LN} \Delta \mathrm{GDH}$ grown in ammonium-rich medium (Fig. 1B). Under these conditions a considerable amount of unmodified GlnK was observed in the cells. Therefore, a contribution to nitrogen regulation of both, 2-oxoglutarate and ammonium can be assumed (Fig. 4).

\subsection{A marker for nitrogen supply: L-glutamine versus ammonium}

In enterobacteria, 2-oxoglutarate is a marker of nitrogen supply besides L-glutamine. As indicated by the data presented here and by previously published experiments (Nolden et al., 2001b) in C. glutamicum ammonium rather than L-glutamine might be a second effector molecule which indicates the cellular nitrogen status. To support this hypothesis, we again used a mutant strain with blocked ammonium metabolism, in this case $g \ln A$ deletion strain LN $\Delta \mathrm{GS}$, which lacks glutamine synthetase and is as a consequence glutamine-auxotrophic. LN $\Delta$ GS cells were cultivated in medium containing ammonium and glutamine as nitrogen sources and subsequently incubated in medium without any nitrogen source for $30 \mathrm{~min}$. After this time, ammonium, glutamine or ammonium and glutamine together were added to the nitrogenstarved cells, which were then cultivated for another $30 \mathrm{~min}$. Transcription of the $g l t B$ gene was analyzed by RNA dot blot hybridization (Fig. 5A). In addition, the internal concentrations of L-glutamine, ammonium, 2- oxoglutarate and L-glutamate were measured by HPLC and $\mathrm{GC}$, respectively.

The presence of ammonium correlated with the transcription level of gltB under all tested conditions (Fig. 5A and B). Transcription of gltB was repressed under high internal concentrations of ammonium $\left(+\mathrm{gln}+\mathrm{NH}_{4}{ }^{+}: 604 \mathrm{mM}\right.$; gln- $\mathrm{NH}_{4}{ }^{+}$-pulse: $478 \mathrm{mM}$; $\mathrm{NH}_{4}{ }^{+}$-pulse: $450 \mathrm{mM}$ ), and activated under low internal concentrations of ammonium ( $-\mathrm{N}$ : $24 \mathrm{mM}$; glnpulse: $26 \mathrm{mM}$ ). In contrast, the internal concentration of glutamine was not correlated to the transcription level of $g l t B$, thus, was not decisive for nitrogen control (Fig. 5A and C). After the addition of ammonium to a culture of nitrogen-starved cells, the glutamine pool was almost unaltered compared to nitrogen starvation $\left(-\mathrm{N}\right.$ : $6.8 \mathrm{mM}$ glutamine; $\mathrm{NH}_{4}{ }^{+}$-pulse: $10.3 \mathrm{mM}$ glutamine), nevertheless, transcription of glt $B$ was repressed. Vice versa, gltB was still transcribed after the addition of glutamine to a culture of nitrogenstarved cells even though the internal concentration of glutamine increased significantly to $81 \mathrm{mM}$. In the $g \ln A$ deletion strain the internal 2-oxoglutarate concentration was low $(1.05 \mathrm{mM}) 30 \mathrm{~min}$ after the glutamine pulse (Fig. 5D), which might be explained by the action of glutamate synthase converting glutamine and 2-oxoglutarate to glutamate. As indicated by the investigation of strain LN $\Delta$ GDH (Fig. 1B), 2-oxoglutarate seems not function as the only effector molecule in $C$. glutamicum. Glutamate could again be excluded as a trigger of nitrogen control since its internal concentration was more or less unaltered under the tested conditions (Fig. 5E).

\subsection{External versus internal ammonium as a putative indicator of nitrogen supply}

Due to the experimental design and the membrane permeability of ammonium in its uncharged form ammonia, it was unclear if the internal or the external concentration of ammonium was sensed by $C$. glutamicum, as both correlated with the transcription of gltB. This question was addressed by a combination of RNA hybridization and feeding experiments. While ammonium is the preferred nitrogen source of C. glutamicum, also other nitrogen sources are metabolized by this organism (for review, see Burkovski, 2003a,b, 2005). These can be used to test whether external or internal ammonium indicates nitrogen supply in a $C$. 
$\begin{array}{llllllll}1 & 2 & 3 & 4 & 5 & 6 & 7 & 8\end{array}$
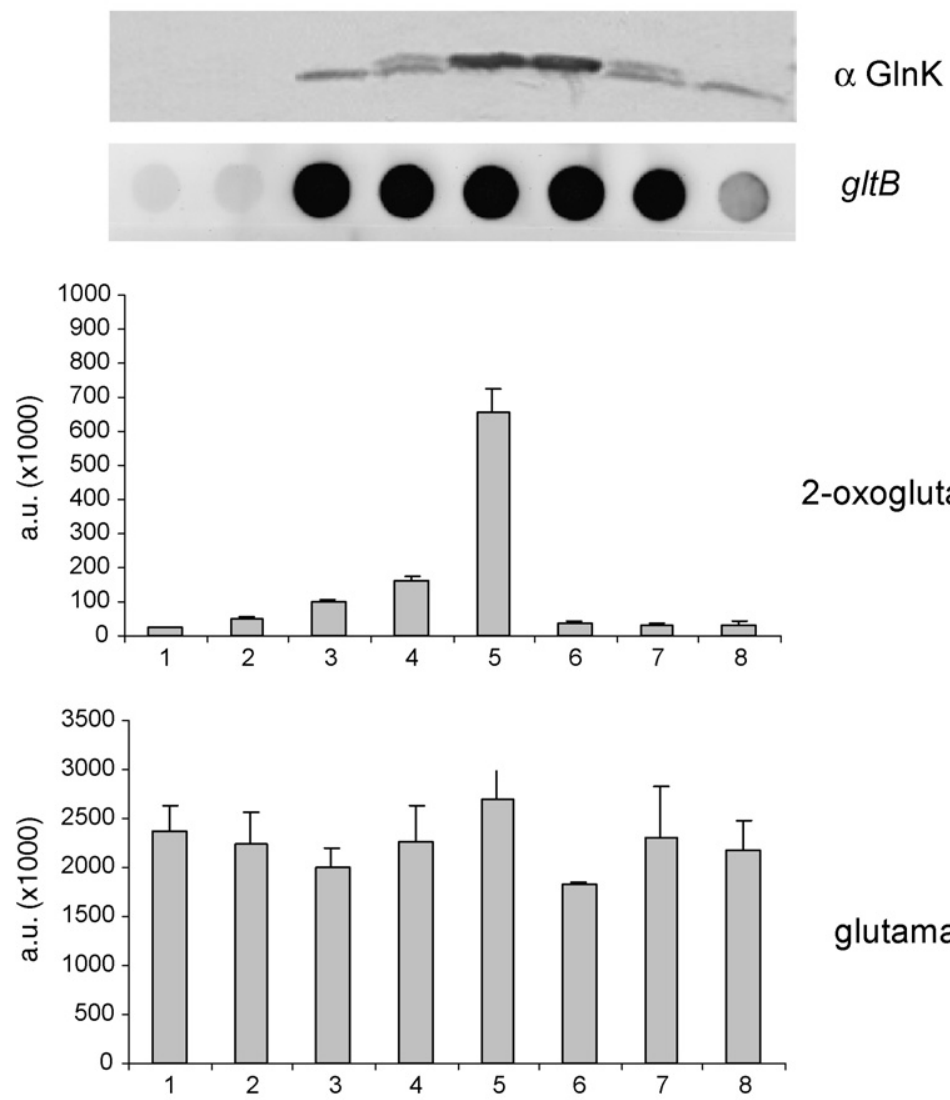

\section{2-oxoglutarate}

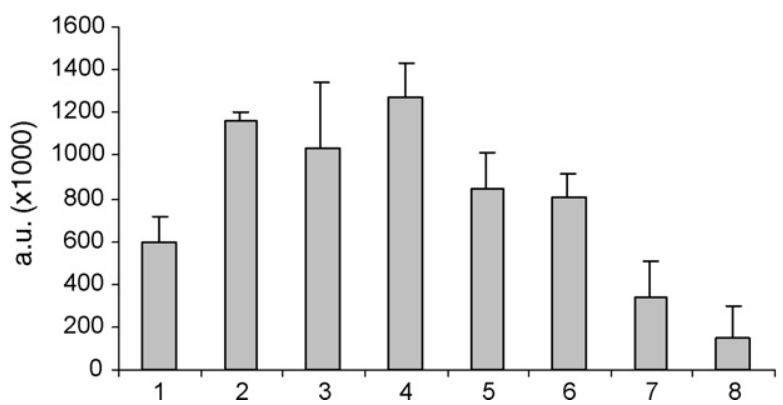

glutamate

glutamine

Fig. 4. Transient alterations of GlnK modification, gltB transcription and metabolite pools. Wild type strain ATCC 13032 was cultivated in nitrogen-rich minimal medium, harvested and transferred to nitrogen-free minimal medium and subsequently treated with an ammonium pulse $(200 \mathrm{mM})$. Synthesis and adenylylation of GlnK was monitored by Western blotting, gltB transcription by RNA hybridization experiments and metabolite pools were analyzed by gas chromatography/mass spectrometry. Samples were taken from nitrogen-supplied cells (1), immediately, 5,15 and $30 \mathrm{~min}$ after transfer in nitrogen-free medium (2-5; for medium exchange cells were harvested by 5 min of centrifugation) and immediately, 5 and $15 \mathrm{~min}$ after addition of $200 \mathrm{mM}$ ammonium (6-8). 


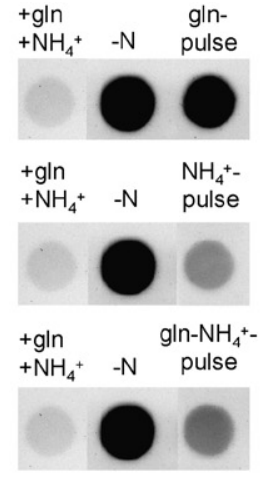

(A)
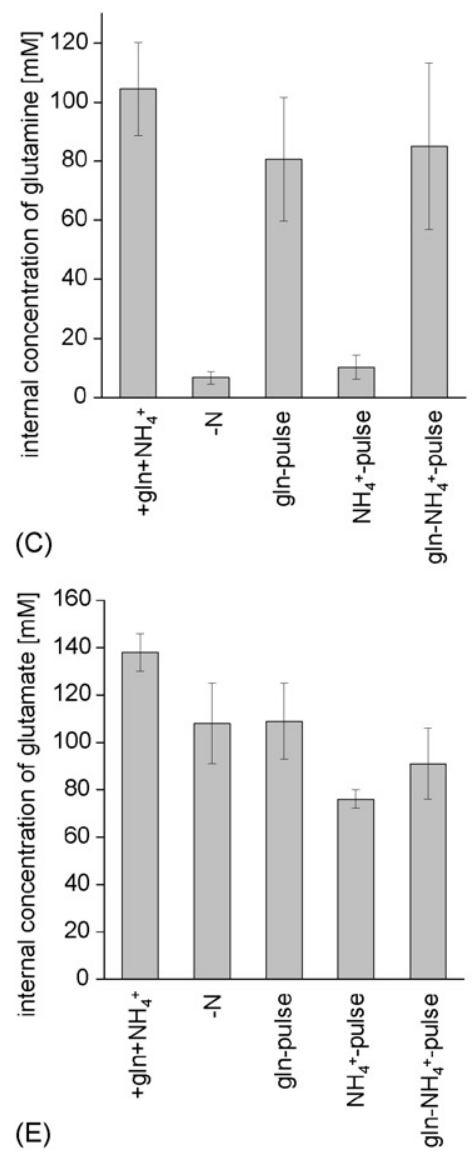
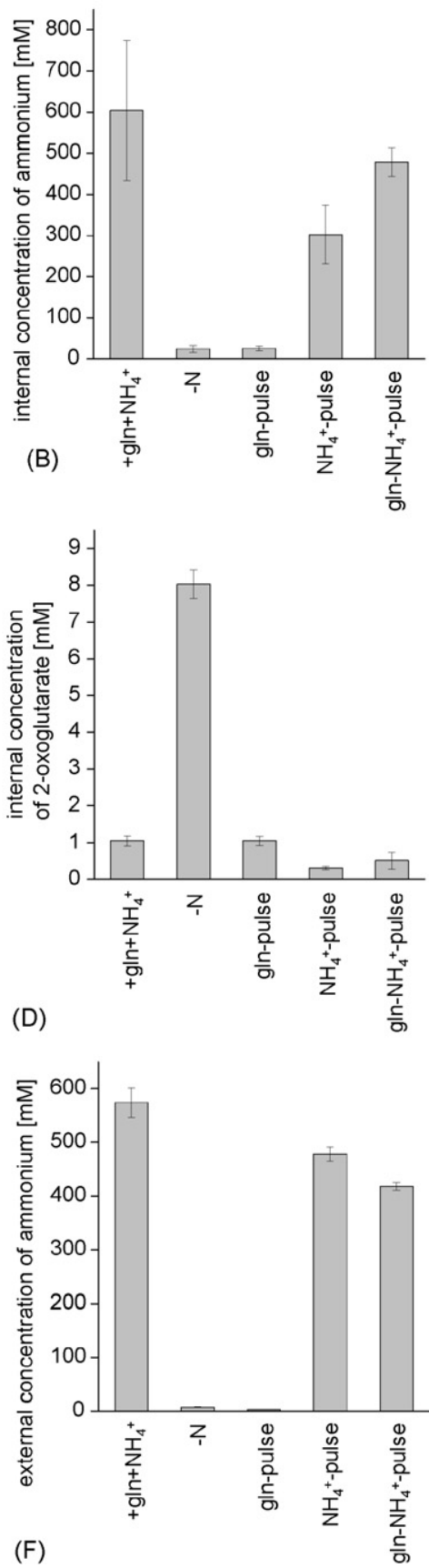

Fig. 5. Transcription of $g d h$ and intracellular metabolite concentrations in $g \ln A$ strain LN $\Delta$ GS. The $g \ln A$ deletion strain LN $\Delta$ GS was cultivated in medium containing ammonium and glutamine as nitrogen sources $\left(+\mathrm{gln}+\mathrm{NH}_{4}{ }^{+}\right)$. Then, the cells were cultivated in medium without any nitrogen source for $30 \mathrm{~min}(-\mathrm{N})$. After that, either ammonium $\left(\mathrm{NH}_{4}{ }^{+}\right.$-pulse) or glutamine (gln-pulse) or ammonium and glutamine $\left(\mathrm{gln}-\mathrm{NH}_{4}{ }^{+}-\right.$ pulse) were added to the nitrogen-starved cells, which were then cultivated for another $30 \mathrm{~min}$. Total RNA was isolated and analyzed by RNA dot blot hybridization using $g l t B$ as probe (A). The internal concentrations of ammonium (B), glutamine (C), 2-oxoglutarate (D), and glutamate (E) as well as the external concentration of ammonium (F) were measured by HPLC and GC, respectively. 


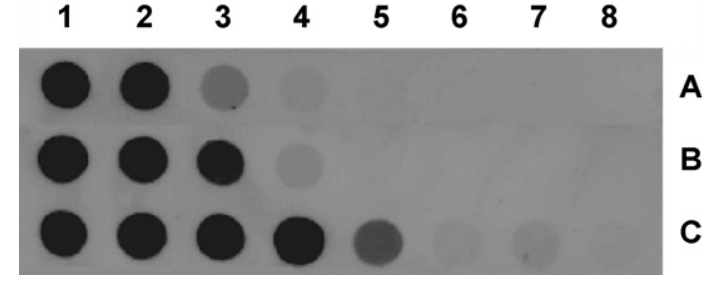

Fig. 6. Influence of different nitrogen sources on the expression of AmtR-regulierted genes. Total RNA was isolated from wild type ATCC 13032 after incubation in nitrogen-free medium for $1.5 \mathrm{~h}$ (1) and after addition of $100 \mathrm{mM}$ ammonium sulfate (A), urea (B) and creatinine (C), respectively, and incubation for 5, 10, 20, $30 \mathrm{~min}, 1$, 2 and $4 \mathrm{~h}(2-8)$. The RNA was hybridized with a gltB probe.

glutamicum cell. For this purpose, urea and creatinine were chosen and added to nitrogen-starved cells. These two nutrients are not extracellularly degraded but are transported into the cell and decomposed intracellularly either by urease leading to ammonium and carbon dioxide (Siewe et al., 1998) or by creatinine deaminase (Bendt et al., 2004) leading to methylhydantoin and ammonium inside the cell. As a marker for nitrogen limitation, $g l t B$ expression was monitored (Fig. 6). RNA hybridization revealed that $g l t B$ is transcribed in the wild type in the absence of nitrogen sources, while ammonium addition blocks gltB expression within $10 \mathrm{~min}$. Interestingly, also addition of urea and creatinine blocks transcription, which indicates that internal rather than external ammonium indicates the nitrogen supply.

\section{Discussion}

When C. glutamicum wild type cells are growing in nitrogen-rich standard minimal media, transcription of $g l t B D$ and $g \ln A$ is repressed by the master regulator of nitrogen control, AmtR (Beckers et al., 2001, 2005; Nolden et al., 2001a). In a $g d h$ mutant strain grown under high ammonium supply this would lead to a situation in which ammonium assimilation would be limited to low glutamine synthetase activity while glutamate generation would be highly impaired due to the lack of $g l t B D$ transcription. However, it was reported previously that deletion of $g d h$ has no obvious effect on growth and glutamate production (Börmann et al., 1992; Börmann-El Kholy et al., 1993). In this study, we found that a $C$. glutamicum $g d h$ deletion strain shows transcription of genes typically repressed by AmtR during nitrogen surplus, including the $g \ln A$ gene and the $g l t B D$ operon which encode the GS/GOGAT pathway for ammonium assimilation. Thus, deletion of $g d h$ causes relief of AmtR-dependent repression, which allows circumventing the putatively detrimental effects of a lacking glutamate dehydrogenase.

Central metabolites of nitrogen metabolism, i.e. ammonium, glutamine, glutamate and 2-oxoglutarate, were analyzed in the wild type and in strains $\mathrm{LN} \Delta \mathrm{GDH}$ and $\mathrm{LN} \Delta \mathrm{GS}$. Based on these investigations, it is very unlikely that glutamate and glutamine indicate the cellular nitrogen status in C. glutamicum wild type cells. Our studies hint to 2-oxoglutarate as marker metabolite that indicates nitrogen supply of $C$. glutamicum, since the release of repression by AmtR in the $g d h$ deletion strain under nitrogen surplus was correlated to intracellular accumulation of 2-oxoglutarate due to the absence of 2-oxoglutarate-consuming GDH. Ammonium seems to be a second effector molecule of nitrogen regulation. Data obtained by the feeding of nitrogen sources, which are intracellularly decomposed, indicate that internal rather than external ammonium is sensed by $C$. glutamicum.

The sensory proteins responsible to monitor the nitrogen status in $C$. glutamicum are still unknown. The most likely candidate for the sensing of 2-oxoglutarate is the $\mathrm{P}_{\mathrm{II}}$-type signal transduction protein $\mathrm{GlnK}$ (for review, see Arcondéguy et al., 2001; Ninfa and Jiang, 2005). Future binding assays with the isolated protein from C. glutamicum might show whether this protein in fact binds 2-oxoglutarate as shown in other bacteria. For Saccharomyces cerevisiae (Lorenz and Heitman, 1998), Rhodobacter capsulatus (Yakunin and Hallenbeck, 2000) and E. coli (Javelle et al., 2004) a sensory function of Mep/Amt proteins was discussed. Also in this case, new efforts are necessary to show, whether C. glutamicum Amt proteins AmtA and/or $\mathrm{AmtB}$ are involved in ammonium sensing or if an independent sensor mechanism is realized in this bacterium.

\section{Acknowledgements}

The authors wish to thank Anja Wittmann for excellent technical assistance, George Coupland for helpful discussions and interest in the project and Dietmar Schomburg for support. 


\section{References}

Abe, S., Takayama, K., Kinoshita, S., 1967. Taxonomical studies on glutamic acid-producing bacteria. J. Gen. Microbiol. 13, 279-301.

Arcondéguy, T., Jack, R., Merrick, M., 2001. $\mathrm{P}_{\text {II }}$ signal transduction proteins, pivotal players in microbial nitrogen control. Microbiol. Mol. Biol. Rev. 65, 80-105.

Ausubel, F.M., Brent, R., Kingston, R.E., Moore, D.D., Seidman, J.G., Smith, J.A., Struhl, K., 1987. Current Protocols in Molecular Biology. Greene Publishing Associates and Wiley Interscience, John Wiley and Sons, NY.

Beckers, G., Nolden, L., Burkovski, A., 2001. Glutamate synthase of Corynebacterium glutamicum is not essential for glutamate synthesis and is regulated by the nitrogen status. Microbiology 147, 2961-2970.

Beckers, G., Strösser, J., Hildebrandt, U., Kalinowski, J., Farwick, M., Krämer, R., Burkovski, A., 2005. Regulation of AmtRcontrolled gene expression in Corynebacterium glutamicum: mechanism and characterization of the AmtR regulon. Mol. Microbiol. 58, 580-595.

Bendt, A.K., Beckers, G., Silberbach, M., Wittmann, A., Burkovski, A., 2004. Utilization of creatinine as an alternative nitrogen source in Corynebacterium glutamicum. Arch. Microbiol. 181, 443-450.

Börmann, E.R., Eikmanns, B.J., Sahm, H., 1992. Molecular analysis of the Corynebacterium glutamicum gdh gene encoding glutamate dehydrogenase. Mol. Microbiol. 6, 317-326.

Börmann-El Kholy, E.R., Eikmanns, B.J., Gutmann, M., Sahm, H., 1993. Glutamate dehydrogenase is not essential for glutamate formation in Corynebacterium glutamicum. Appl. Environ. Microbiol. 59, 2329-2331.

Burkovski, A., 2003a. Ammonium assimilation and nitrogen control in Corynebacterium glutamicum and its relatives: an example for new regulatory mechanisms in actinomycetes. FEMS Microbiol. Rev. 27, 617-628.

Burkovski, A., 2003b. I do it my way: regulation of ammonium uptake and ammonium assimilation in Corynebacterium glutamicum. Arch. Microbiol. 179, 83-88.

Burkovski, A., 2005. Nitrogen metabolism and its regulation. In: Bott, M., Eggeling, L. (Eds.), Handbook of Corynebacterium glutamicum. CRC Press LLC, Boca Raton, FL, pp. 333-349.

Chun, J., Kang, S.-O., Hah, Y.C., Goodfellow, M., 1996. Phylogeny of mycolic acid-containing actinomycetes. J. Ind. Microbiol. 17, 205-213.

Eikmanns, B.J., Thum-Schmitz, N., Eggeling, L., Lüdtke, K.-U., Sahm, H., 1994. Nucleotide sequence, expression and transcriptional analysis of the Corynebacterium glutamicum gltA gene encoding citrate synthase. Microbiology 140, 1817-1828.

Grant, S.N.G., Jessee, J., Bloom, F.R., Hanahan, D., 1990. Differential plasmid rescue from transgenic mouse DNAs into Escherichia coli methylation-restriction mutants. Proc. Natl. Acad. Sci. U.S.A 87, 4645-4649.

Hermann, T., 2003. Industrial production of amino acids by coryneform bacteria. J. Biotechnol. 104, 155-172.

Jakoby, M., Tesch, M., Sahm, H., Krämer, R., Burkovski, A., 1997. Isolation of the Corynebacterium glutamicum glnA gene encoding glutamine synthetase I. FEMS Microbiol. Lett. 154, $81-88$.

Jakoby, M., Nolden, L., Meier-Wagner, J., Krämer, R., Burkovski, A., 2000. AmtR, a global repressor in the nitrogen regulation system of Corynebacterium glutamicum. Mol. Microbiol. 37, 964-977.

Javelle, A., Severi, E., Thornton, J., Merrick, M., 2004. Ammonium sensing in Escherichia coli. Role of the ammonium transporter AmtB and AmtB-GlnK complex formation. J. Biol. Chem. 279, 8530-8538.

Keilhauer, C., Eggeling, L., Sahm, H., 1993. Isoleucine synthesis in Corynebacterium glutamicum: molecular analysis of the ilvB$i l v N$-ilvC operon. J. Bacteriol. 175, 5595-5603.

Kimura, K., 1962. The significance of glutamic dehydrogenase in glutamic acid fermentation. J. Gen. Appl. Microbiol. 8, 253-260.

Kinoshita, S., Udaka, S., Shimono, M., 1957. Amino acid fermentation. I. Production of L-glutamic acid by various microorganisms. J. Gen. Appl. Microbiol. 3, 193-205.

Leuchtenberger, W., 1996. Amino acids-technical production and use. In: Roehr, M. (Ed.), Biotechnology, vol. VI. VCH, Weinheim.

Lindroth, P., Mopper, K., 1979. High performance liquid chromatography determination of subpicomole amounts of amino acids by precolumn flourescnce derivatization with $o$-phthaldialdehyde. Anal. Chem. 51, 1667-1674.

Lorenz, M.C., Heitman, J., 1998. The MEP2 ammonium permease regulates pseudohyphal differentiation in Saccharomyces cerevisiae. EMBO J. 17, 1236-1247.

Ninfa, A.J., Jiang, P., 2005. PII signal transduction proteins: sensors of alpha-ketoglutarate that regulate nitrogen metabolism. Curr. Opin. Microbiol. 8, 168-173.

Nolden, L., Farwick, M., Krämer, R., Burkovski, A., 2001a. Glutamine synthetases in Corynebacterium glutamicum: transcriptional control and regulation of activity. FEMS Microbiol. Lett. 201, 91-98.

Nolden, L., Ngouoto-Nkili, C.-E., Bendt, A.K., Krämer, R., Burkovski, A., 2001b. Sensing nitrogen limitation in Corynebacterium glutamicum: the role of $g \ln K$ and $g \ln D$. Mol. Microbiol. 42, 1281-1295.

Oshima, K., Tanaka, K., Kinoshita, S., 1964. Studies on L-glutamic acid fermentation. Part XI. Purification and properties of Lglutamic acid dehydrogenase from Micrococcus glutamicus. Agric. Biol. Chem. 28, 714-722.

Rönsch, H., Krämer, R., Morbach, M., 2003. Impact of osmotic stress on volume regulation, cytoplasmic solute composition and lysine production in Corynebacterium glutamicum MH20-22B. J. Biotechnol. 104, 87-97.

Sambrook, J., Fritsch, E.F., Maniatis, T., 1989. Molecular Cloning: A Laboratory Manual, 2nd ed. Cold Spring Habor Laboratory Press, Cold Spring Habor, NY.

Schäfer, A., Tauch, A., Jäger, W., Kalinowski, J., Thierbach, G., Pühler, A., 1994. Small mobilizable multi-purpose cloning vectors derived from the Escherichia coli plasmids pK18 and pK19: selection of defined deletions in the chromosome of Corynebacterium glutamicum. Gene 145, 69-73.

Schägger, H., von Jagow, G., 1987. Tricine-sodium dodecyl sulfatepolyacrylamide gel electrophoresis for the separation of proteins in the range from 1 to $100 \mathrm{kDa}$. Anal. Biochem. 166, 368-379. 
Schulz, A.A., Collett, H.J., Reid, S.J., 2002. Regulation of glutamine synthetase and glutamate synthase in Corynebacterium glutamicum ATCC 13032. FEMS Microbiol. Lett. 205, 361-367.

Shiio, I., Ozaki, H., 1970. Regulation of nicotinamide adenine dinucleotide phosphate-specific glutamate dehydrogenase from Brevibacterium flavum, a glutamate-producing bacterium. J. Biochem. 68, 633-647.

Siewe, R.M., Weil, B., Burkovski, A., Eggeling, L., Krämer, R., Jahns, T., 1998. Urea uptake and urease activity in Corynebacterium glutamicum. Arch. Microbiol. 169, 411-416.

Strelkov, S., von Elstermann, M., Schomburg, D., 2004. Comprehensive analysis of metabolites in Corynebacterium glutamicum by gas chromatography/mass spectrometry. Biol. Chem. 385 , 853-861.

Strösser, J., Lüdke, A., Schaffer, S., Kämer, R., Burkovski, A., 2004. Regulation of GlnK activity: modification, membrane sequestration and proteolysis as regulatory principles in the network of nitrogen control in Corynebacterium glutamicum. Mol. Microbiol. 54, 132-147.

Tesch, M., Eikmanns, B.J., de Graaf, A.A., Sahm, H., 1998. Ammonia assimilation in Corynebacterium glutamicum and a gluta- mate dehydrogenase-deficient mutant. Biotechnol. Lett. 20, $953-$ 957.

Tochikura, T., Sung, H.-C., Tachiki, T., Kumagai, H., 1984. Occurence of glutamate synthase in Brevibacterium flavum. Agric. Biol. Chem. 48, 2149-2150.

Udaka, S., 1960. Screening method for microorganisms accumulating metabolites and its use in the isolation of Micrococcus glutamicus. J. Bacteriol. 79, 745-755.

van den Dool, H., Kratz, P.D., 1963. A generalization of the retention index system including linear temperature programmed gas-liquid partition chromatography. J. Chromatogr. 11, 463471.

van der Rest, M.E., Lange, C., Molenaar, D., 1999. A heat shock following electroporation induces highly efficient transformation of Corynebacterium glutamicum with xenogenic plasmid DNA. Appl. Microbiol. Biotechnol. 52, 541-545.

Yakunin, A.F., Hallenbeck, P.C., 2000. AmtB is Necessary for $\mathrm{NH}_{4}{ }^{+}$Induced Nitrogenase Switch-off and ADP-Ribosylation in Rhodobacter capsulatus. In: Nitrogen Fixation: From Molecules to Crop Productivity. Kluwer Academic, Dordrecht, The Netherlands, pp. 95-96. 